\title{
Beyond Copper: Novel Ni Foam Catalysts for Sustainable Nitrate to Ammonia Electroreduction
}

\author{
Anna Iarchuk ${ }^{1,2}$, Abhijit Dutta $^{1} *$ and Peter Broekmann*1,2 \\ ${ }^{1}$ Department of Chemistry, Biochemistry and Pharmaceutical Science, University of Bern, \\ Freiestrasse 3, 3012 Bern, Switzerland \\ ${ }^{2}$ National Centre of Competence in Research (NCCR) Catalysis, University of Bern, \\ Freiestrasse 3, 3012 Bern, Switzerland \\ *Corresponding authors: abhijit.dutta@unibe.ch (A. Dutta) and \\ peter.broekmann@unibe.ch (P.Broekmann) \\ $\dagger$ Electronic supplementary information (ESI) available.
}

\begin{abstract}
Electrochemical nitrate reduction $\left(\mathrm{NO}_{3}^{-} \mathrm{RR}\right)$ is considered a promising energy efficient approach to remove environmentally harmful nitrate from various types of wastewater while simultaneously producing a product with high added value: ammonia $\left(\mathrm{NH}_{3}\right)$. One important factor to be accounted for is the choice of the catalyst, which is required not only to accelerate $\mathrm{NO}_{3}^{-} \mathrm{RR}$ but also to direct the product selectivity of the electrolysis toward ammonia production. To this end, herein, we demonstrate the fabrication of novel Ni foam catalysts produced by means of a dynamic hydrogen bubble template and additive assisted electrodeposition process. The resulting 3D foam morphology of the catalyst is demonstrated to crucially govern its overall catalytic performance. Post-electrolysis cross-sectional SEMEDX analysis (K mapping) demonstrated complete wetting of the 3D foam structure by the electrolyte. Ni foams deposited within $20 \mathrm{~s}$ (foam thickness of $\mathrm{h} \sim 22 \mu \mathrm{m}$; Ni foam mass loading of $\mathrm{m}_{\mathrm{Ni}}=2.6 \mathrm{mg} \cdot \mathrm{cm}^{-2}$ ) exhibited outstanding selectivity toward nitrate electroreduction: more than $95 \%$ of the Faradaic efficiency $\left(\mathrm{FE}_{\mathrm{NH} 3}\right)$ of ammonia production was achieved in the particularly low potential range from -0.1 to $-0.3 \mathrm{~V}$ vs. RHE. Hydrogen was found to be the only minor by-product of the nitrate reduction. Intriguingly, no other nitrogen containing products (e.g., $\mathrm{NO}, \mathrm{N}_{2} \mathrm{O}$, and $\mathrm{N}_{2}$ ) formed during electrolysis, thus indicating a highly efficient (nitrate $\rightarrow$ ammonia) conversion process. This significant improvement over the use of a planar $\mathrm{Ni}$ foil reference (33\% $\mathrm{FE}_{\mathrm{NH} 3}$ at $-0.3 \mathrm{~V} v s$. RHE) is attributable to (i) the effective suppression of the HER in this potential regime and (ii) a high surface density of active sites for the nitrate reduction formed during $\mathrm{Ni}$ foam electrodeposition under extreme experimental conditions, e.g., at an applied geometric current density of $-3 \mathrm{~A} \mathrm{~cm}^{-2}$. Trapping $\mathrm{NO}_{3}^{-} \mathrm{RR}$ intermediates inside the primary
\end{abstract}


macroporosity contributed to the excellent catalytic performance of the Ni foams. Identical location (IL) SEM analyses demonstrated the excellent structural stability of the novel $\mathrm{Ni}$ foam during extended catalyst stressing. These superior characteristics have not previously been reported for $\mathrm{Ni}$ and $\mathrm{Ni}$ rich catalysts, thus making the novel foam type of catalyst a highly promising candidate for truly selective and energy efficient (nitrate $\rightarrow$ ammonia) electroreduction and a promising alternative to mature copper-based $\mathrm{NO}_{3}^{-} \mathrm{RR}$ catalysts.

\section{Introduction}

In the past several decades, numerous anthropogenic activities (e.g., intensive farming) have led to substantial perturbations of the nitrogen cycle..$^{1-4}$ In particular, nitrate pollution in soil and groundwater has become a serious environmental threat with high potential to affect human health and consequently destabilize entire ecosystems worldwide. ${ }^{5}$ The continually increasing production and use of nitrogenbased fertilizers ${ }^{1}$ (e.g., ammonium nitrate and ammonium sulfate) along with other industrial activities (e.g., generation of low-level nuclear wastewater ${ }^{6,7}$ and production of pharmaceuticals ${ }^{8}$ ) generate billions of tons of nitrate-containing wastewater annually. ${ }^{9}$ This unfortunate development has resulted in a steady increase in nitrate $\left(\mathrm{NO}_{3}^{-}\right)$concentrations in surface waters and groundwaters, and alarmingly high nitrate concentrations of $1500 \mathrm{mg} \cdot \mathrm{L}^{-1}$ have been observed in heavily polluted areas. ${ }^{10}$ According to the recommendations of the World Health Organization, the maximum nitrate concentration in drinking water should be limited to below $50 \mathrm{mg} \cdot \mathrm{L}^{-1} \cdot{ }^{8,11}$ High concentrations of nitrate (and nitrite) in drinking water can lead to methemoglobinemia in infants and gastrointestinal cancer in adults. ${ }^{11}$

One major anthropogenic contribution to the nitrogen cycle and its perturbation is the Haber-Bosch process $^{1,3}$, which is used to produce more than 150 million tons of ammonia annually. ${ }^{12}$ Ammonia is among the most important platform chemicals in the chemical industry and an essential raw material for the production of fertilizers on large industrial scales. ${ }^{12}$ Ammonia synthesis requires the high-temperature and high-pressure reaction of nitrogen and hydrogen, which not only consumes enormous amounts of energy but also substantially adds to anthropogenic $\mathrm{CO}_{2}$ emissions, because the required hydrogen is typically derived from environmentally harmful steam reforming processes. ${ }^{12,13}$ The electrochemical conversion of nitrate therefore has high potential to contribute to both (i) the removal of environmentally harmful nitrates from various forms of wastewater ${ }^{6-8}$ and (ii) the sustainable production of "green" ammonia. ${ }^{6,14}$ In this respect, electrochemical nitrate reduction $\left(\mathrm{NO}_{3}^{-} \mathrm{RR}\right)$ to ammonia clearly surpasses the mature methods of non-electrochemical wastewater treatment, whose aim is only to separate nitrate from wastewater. These methods are often based on ion exchange ${ }^{15}$, reverse osmosis ${ }^{16}$, or electrodialysis ${ }^{17}$. In addition, electrolysis approaches have been used to remove nitrate from wastewater, but again only with the aim to transform nitrate into dinitrogen, a process often referred to as denitrification. ${ }^{6,18}$ 
In the future, $\mathrm{NO}_{3}^{-} \mathrm{RR}$ to ammonia might become not only economically feasible but also truly sustainable, particularly when surplus renewable energy from solar radiation, wind power, and hydroelectric sources is used as an energy input for the endergonic nitrate reduction. Among other electrocatalytic processes (e.g., $\mathrm{CO}_{2} \mathrm{RR}^{19-21}$ and $\mathrm{N}_{2} \mathrm{RR}^{13,22}$ ), $\mathrm{NO}_{3}^{-} \mathrm{RR}$ to ammonia is considered a key element of the "power-to-X" approach. Of note, ammonia not only is a valuable intermediate in chemical industry but also, owing to its high energy density of $4.3 \mathrm{kWh} \mathrm{kg}^{-1}$, is a highly promising carbon-free energy carrier expected to play a key role in the "energy transition". 13, 23, 24

Several experimental factors govern the product selectivity of an electrocatalyzed reaction and are commonly expressed in terms of the Faradaic efficiency (FE) or the corresponding partial current density (PCD). Among these factors, the choice of the catalyst/electrode material most strongly influences the resulting product distribution and the achievable partial and total current densities (TCDs). Precious metals, such as $\mathrm{Pt}^{25-27}, \mathrm{Rh}^{27}$, and $\mathrm{Ru}^{28}$, have been reported to be active toward $\mathrm{NO}_{3}^{-} \mathrm{RR}$ but to partially favor other products than ammonia (e.g., $\mathrm{NO}_{2}^{-}$and $\mathrm{N}_{2}$ ). Their $\mathrm{NO}_{3}^{-} \mathrm{RR}$ performance is often limited by the parasitic hydrogen evolution reaction (HER), which occurs on these catalyst materials at high rates at particularly low applied overpotentials, thus interfering with the targeted $\mathrm{NO}_{3}^{-} \mathrm{RR}^{26}$ In addition, the high material costs in combination with material scarcity will impede the use of these precious metals in future $\mathrm{NO}_{3}^{-} \mathrm{RR}$ applications. Therefore, research efforts are currently directed toward the development of more abundant, lower-cost $\mathrm{NO}_{3}^{-} \mathrm{RR}$ electrocatalysts. The literature has reported that $\mathrm{Cu}$ based materials exhibit excellent performance toward $\mathrm{NO}_{3}^{-} \mathrm{RR}$, yielding ammonia as the main electrolysis product. ${ }^{23}$, ${ }^{29}$ However, previous studies have also demonstrated that pure $\mathrm{Cu}$ catalysts often experience oxidative dissolution and irreversible surface poisoning, both of which lead to undesired catalyst degradation. ${ }^{30}$ The further improvement of known catalyst materials and the search for new catalyst concepts therefore must address $\mathrm{NO}_{3}^{-} \mathrm{RR}$ product selectivity, and particularly the structural and chemical stability of the catalyst during extended electrolysis. For example, Wang et al. have reported that co-alloying of $\mathrm{Cu}$ with $50 \%$ of $\mathrm{Ni}$ significantly improves $\mathrm{NO}_{3}^{-} \mathrm{RR}$ performance, which can be performed at particularly low applied overpotentials $\left(\mathrm{FE}_{\mathrm{NH} 3}=99 \%\right.$; $\mathrm{PCD}_{\mathrm{NH} 3}=90 \mathrm{~mA} \cdot \mathrm{cm}^{-2}$ achieved in $1 \mathrm{M} \mathrm{KOH}+100 \mathrm{mM} \mathrm{KNO} 3, \mathrm{pH} 14, \mathrm{E}=$ $-0.1 \mathrm{~V} v s$. reversible hydrogen electrode (RHE)). ${ }^{31}$ In tandem with this improvement in energy efficiency, this binary $\mathrm{CuNi}$ alloy has demonstrated higher stability than that of pure $\mathrm{Cu}$ catalysts. ${ }^{31}$ However, a further increase in $\mathrm{Ni}$ content up to $70 \%$ causes a substantial loss in $\mathrm{NO}_{3}^{-} \mathrm{RR}$ selectivity, resulting in a comparably low Faradaic efficiency of only $\mathrm{FE}_{\mathrm{NH} 3}=38 \%(1 \mathrm{M} \mathrm{KOH}+1 \mathrm{mM} \mathrm{KNO}, \mathrm{pH} 14, \mathrm{E}=-0.06 \mathrm{~V}$ vs. RHE).$^{31}$ In apparent accordance with this reported trend, pure nanoparticulate Ni catalysts exhibit an even lower $\mathrm{FE}_{\mathrm{NH} 3}$ value of only $11 \%\left(1 \mathrm{M} \mathrm{KOH}+1 \mathrm{mM} \mathrm{KNO}_{3}, \mathrm{pH} 14, \mathrm{E}=-0.06 \mathrm{~V} v\right.$. RHE $) .{ }^{31} \mathrm{The}$ electrocatalytic performance of commercial $\mathrm{Ni}$ foams has been studied by Zheng et al. ${ }^{32}$, who have reported a Faradaic efficiency of $\mathrm{FE}_{\mathrm{NH} 3}=53.3 \%$. $\mathrm{NH}_{3}$ selectivity can be further increased through self- 
activation of the Ni electrodes, which has been reported to originate from in situ formation of an $\mathrm{Ni}(\mathrm{OH})_{2}$ film on the $\mathrm{Ni}$ support (denoted $\left.\mathrm{Ni}(\mathrm{OH})_{2} @ \mathrm{Ni}\right){ }^{32}$ However, the mechanistic origin of this substantial performance improvement remains unresolved. Several studies have emphasized the eminent role of catalyst morphology in the resultant $\mathrm{NO}_{3}^{-}$have efficiency. ${ }^{23,}{ }^{29,}{ }^{31}$ In this context, Wang et al. ${ }^{33}$ have compared commercially available $\mathrm{Ni}$ foams (sponges) with $\mathrm{CuNi}$ composite materials derived from $\mathrm{Cu}$ deposition onto the $\mathrm{Ni}$ foam support. The electrodeposited porous $\mathrm{Cu}$ layer introduces additional active sites to the catalyst, thus increasing the nitrate removal efficiency from $10 \%$ to $99.2 \%$. However, the $\mathrm{CuNi}$ composite catalyst has been found to remain non-selective regarding the final $\mathrm{NO}_{3}^{-} \mathrm{RR}$ product $\left(\mathrm{NH}_{3}, \mathrm{~N}_{2}\right.$, etc. $){ }^{33}$

Reports describing high $\mathrm{NO}_{3}^{-} \mathrm{RR}$ performance of pure $\mathrm{Ni}$ or Ni-rich electrocatalysts are still rare. The present work demonstrates that highly porous $\mathrm{Ni}$ foams electrodeposited onto a $\mathrm{Ni}$ foil support exhibit superior electrocatalytic characteristics, achieving more than $95 \%$ of FE of ammonia production in the low potential range from -0.1 to $-0.3 \mathrm{~V}$ vs. RHE. The dynamic hydrogen bubble template (DHBT) electrodeposition approach, using a high geometric current density of $-3 \mathrm{~A} \cdot \mathrm{cm}^{-2}$, is demonstrated herein to be a facile and fast method for the fabrication of Ni foams within 10-60 s without the need for further catalyst activation, e.g., in the form of thermal annealing or anodization. We demonstrate that these pure $\mathrm{Ni}$ foam catalysts show superior performance toward $\mathrm{NO}_{3}^{-} \mathrm{RR}$ in terms of product selectivity and catalyst durability, thus making them a viable alternative to mature copper-based $\mathrm{NO}_{3}^{-} \mathrm{RR}$ catalysts.

\section{Experimental methods}

The Ni foams used as $\mathrm{NO}_{3}^{-} \mathrm{RR}$ catalysts were fabricated through the $\mathrm{DHBT}^{34,35}$ assisted electrodeposition process with as-received Ni foils (Fig. S1, ESI $\dagger$ ) serving as the support electrode $(0.25 \mathrm{~mm}$ thick, Alfa Aesar, $99.5 \%$ metal basis). The geometric surface area exposed to the electrolyte was $1 \mathrm{~cm}^{2}$. This surface area was delineated by masking the Ni foil supports with PTFE tape before electrodeposition (Fig. S2, ESI $\dagger$ )). The aqueous plating bath $(\mathrm{pH} \sim 4.5)$ contained $1.5 \mathrm{M} \mathrm{NH} \mathrm{Cl}_{4}$ (Sigma-Aldrich, $\geq 99.5 \%$ ) as the supporting electrolyte, $0.12 \mathrm{M} \mathrm{NiSO}_{4}$ (Sigma-Aldrich, $\geq 98 \%$ ) as the $\mathrm{Ni}$ source, and $0.2 \mathrm{mg} \cdot \mathrm{L}^{-1}$ polyalkylene glycol (PAG: poly(ethylenglycol)-block-poly(propyleneglycol)-block-poly(ethylenglycol), Sigma-Aldrich, $\left.\mathrm{M}_{\mathrm{w}}=8400 \mathrm{~g} \cdot \mathrm{mol}^{-1}\right)$ as a plating additive. The galvanostatic electrodeposition process was conducted with a three-electrode setup (Fig. S3a, ESI $\dagger$ ), wherein the masked Ni foil served as the working electrode (WE), a Pt foil served as the counter electrode (CE), and a $\mathrm{Ag} / \mathrm{AgCl} \mathrm{l}_{3 \mathrm{M}}$ electrode (Metrohm, double junction design) served as the reference electrode (RE). A geometric current density of $\mathrm{j}_{\text {geo }}=-3 \mathrm{~A} \cdot \mathrm{cm}^{-2}$ was applied for 5, 10, 20, 30, 40, 50, and 60 seconds, thus yielding Ni foams with varying thickness and pore size distribution (Table S1, ESI $\dagger$ ). After emersion from the plating bath, the formed Ni foams were thoroughly rinsed with Milli-Q water (18.2 M $\Omega \mathrm{cm}$ and TOC value below $5 \mathrm{ppb}$, Millipore) 
and kept under Milli-Q water for $\sim 1$ hour to completely remove residual traces of electrolyte (particularly $\mathrm{NH}_{4}^{+}$ions). Of note, $\mathrm{Ni}$ foams were deposited on both sides of the Ni foil support (Fig. S4, ESI $\dagger$ ).

For reference measurements $\mathrm{Ni}$ film catalysts were prepared from electrodeposited $\mathrm{Ni}$ foams (removal of the pore structure). For this purpose electrodeposited Ni foams (20s deposition time) were transferred into a small vial containing iso-propanol followed by sonication in an ultra-sonic bath sonicator. Ni powders were then obtained by evaporating the iso-propanol solvent at $40{ }^{\circ} \mathrm{C}$ for 12 hours. For the ink formulation the dried Ni powders were mixed with isopropanol and $5 \mathrm{w} \%$ Nafion followed by sonication for $30 \mathrm{~min}$. The prepared ink was painted onto a carbon support (type A8, Fuel Cell, USA). The catalyst loading was $\sim 3 \mathrm{mg} \cdot \mathrm{cm}^{-2}$.

X-ray powder diffractograms (XRDs) were recorded with a Bruker D8 diffractometer with $\mathrm{CuK}_{\alpha}$ radiation $(\lambda=0.1540, \mathrm{I}=40 \mathrm{~mA})$ generated at $40 \mathrm{keV}$ acceleration voltage. Diffractograms were measured in the $2 \theta$ range from $10^{\circ}$ to $90^{\circ}$, with a scan rate of $1^{\circ} \cdot \mathrm{min}^{-1}$. The obtained diffractogram patterns were compared with the respective Joint Committee on Powder Diffraction standard for Ni and NiO (Ni-JCPDS: 04-0850, NiO-JCPDS:73-1523).

The surface morphology of the as-received $\mathrm{Ni}$ foils was characterized with atomic force microscopy (Nanosurf FlexAFM V2 system, Tap150A1-G silicon cantilevers) before electrodeposition (Fig. S1, ESI + )). The structural analysis of the Ni foam morphologies was conducted before and after electrolysis through scanning electron microscopy (SEM) with a Zeiss Gemini 450 instrument equipped with an InLens secondary electron and a backscattered electron detector. For the InLens and backscattered electron detection modes, accelerating voltages (electron currents) of $3.0 \mathrm{kV}(100 \mathrm{pA})$ and $20 \mathrm{kV}(1.5 \mathrm{nA})$ were used as standard settings. AZtec 4.2 software (Oxford Instruments) was applied to acquire energy dispersive X-ray (EDX) point spectra and the respective 2D elemental mappings.

All further electrochemical experiments were performed with an H-type electrolysis cell in a threeelectrode configuration (Fig. S3b, ESI†)), where electrodeposited Ni foam served as the WE, a Pt foil served as the $\mathrm{CE}$, and $\mathrm{Ag} / \mathrm{AgCl}_{3 \mathrm{M}}$ (Pine research, $3.5 \mathrm{~mm}$ of outer diameter and $74 \mathrm{~mm}$ of length) served as the RE.

To estimate the electrochemically active surface area (ECSA) of the electrodeposited Ni foam catalysts, we applied two voltammetric approaches based on (i) double layer capacitance and (ii) (Faradaic) peak current measurements. For the capacitance method, cyclic voltammograms were recorded in $0.1 \mathrm{M} \mathrm{KOH}$ (Sigma-Aldrich, reagent grade) solution in the potential range from 0.025 to $0.175 \mathrm{~V} v s$. RHE (Fig. S5a, ESI $\dagger$ ). The applied potential sweep rate was $10 \mathrm{mV} \cdot \mathrm{s}^{-1}$. The current difference at $0.088 \mathrm{~V} v s$. RHE was used for the ECSA estimation (Fig. S5b, ESI $\dagger$ ). For the (Faradaic) peak current method, potential sweeprate dependent $\mathrm{CVs}$ were recorded in an electrolyte solution containing $1 \mathrm{mM}$ dimethyl viologen dichloride ( $\mathrm{DMVCl}_{2}$; Sigma-Aldrich, 98\%) and $0.1 \mathrm{M} \mathrm{K}_{2} \mathrm{SO}_{4}$ (Sigma-Aldrich, $\geq 99.0$ ) in the range from 
10 to $500 \mathrm{mV} \cdot \mathrm{s}^{-1}$ (Fig. S6a-f, ESI $\dagger$ ). The reversible reduction of the dimethyl viologen di-cation $\left(\mathrm{DMV}^{2+}\right)$ to its corresponding radical mono-cation $\left(\mathrm{DMV}^{++}\right)$according to

$$
\mathrm{DMV}^{2+}+\mathrm{e}^{-} \rightleftharpoons \mathrm{DMV}^{++}
$$

was used to probe the ECSA of the Ni foams. ECSA values were estimated on the basis of the RandlesŠevč́́k equation

$$
\mathrm{j}_{\mathrm{p}}=2.69 \cdot 10^{5} \cdot \mathrm{n}^{2 / 3} \cdot \mathrm{A} \cdot \mathrm{c} \cdot \mathrm{D}^{1 / 2} \cdot \mathrm{v}^{1 / 2}
$$

where $\mathrm{j}_{\mathrm{p}}$ refers to the (Faradaic) peak current density (normalized to the geometric surface area of $1 \mathrm{~cm}^{2}$ ), $\mathrm{n}$ is the number of electrons transferred in the reaction, $\mathrm{A}\left(\mathrm{cm}^{2}\right)$ is the ECSA, D $\left(\mathrm{cm}^{2} \cdot \mathrm{s}^{-1}\right)$ is the diffusion coefficient $\left(\mathrm{D}=5.5 \cdot 10^{-6} \mathrm{~cm}^{2} \cdot \mathrm{s}^{-1}\right)$, and $v\left(\mathrm{~V} \cdot \mathrm{s}^{-1}\right)$ is the potential sweep rate. The ECSA values were derived from the linear regression of $\mathrm{j}_{\mathrm{p}} v s$. $v^{1 / 2}$ (Fig. S6g-1, Table S1, ESI $\dagger$ )). Of note, the Randles-Ševčík equation was originally derived for planar disk macro-electrodes rather than the porous materials studied herein. However, several studies have successfully applied this approach to porous electrode materials yielding linear $\mathrm{j}_{\mathrm{p}} v s . v^{1 / 2}$ relationships in the scan-rate dependent $\mathrm{CV}$ measurements, thus confirming the applicability of this method even in cases with non-planar porous electrodes. ${ }^{36-40}$

$\mathrm{NO}_{3}^{-} \mathrm{RR}$ experiments were performed by using an H-type electrolysis cell in a three-electrode configuration (Fig. S3b, ESI $\uparrow$ ), where electrodeposited Ni foam served as the WE, a Pt foil served as the $\mathrm{CE}$, and $\mathrm{Ag} / \mathrm{AgCl}_{3 \mathrm{M}}$ (Pine research) served as the $\mathrm{RE}$. The catholyte and anolyte compartments were separated by an anion exchange membrane (Sustainion X37-50 RT) and filled with $1 \mathrm{M} \mathrm{KOH}$ electrolyte solution ( $\mathrm{pH} \sim 14$ ) containing $0.1 \mathrm{M} \mathrm{KNO}_{3}$ (Sigma-Aldrich, $\geq 99.0 \%$ ). Before electrolysis, the catholyte was purged for 30 min with Ar gas (99.999\%, Carbagas, Switzerland) to remove dissolved oxygen and prevent oxygen reduction reaction, which is considered a further parasitic side-reaction to $\mathrm{NO}_{3}^{-} \mathrm{RR}$. Nitrate electrolyses were performed potentiostatically in the range from $-0.7 \mathrm{~V}$ to $-1.6 v s$. $\mathrm{Ag} / \mathrm{AgCl} \mathrm{l}_{3 \mathrm{M}}$. All electrode potentials reported herein were $i R$-corrected (cell resistance determined with the current interrupt method in Nova software (Autolab)). For comparability, all potentials were further converted to the RHE scale according to:

$$
\mathrm{E}_{\mathrm{RHE}}(\mathrm{V})=\mathrm{E}_{\mathrm{Ag} / \mathrm{AgCl}(3 \mathrm{M})}(\mathrm{V})+0.210 \mathrm{~V}+0.0591 \mathrm{~V} \cdot \mathrm{pH}
$$

Aliquots of the catholyte were collected after $30 \mathrm{~min}$ of electrolysis and subjected to quantitative ammonia analysis through the standard indophenol blue method (Fig. S7a, ESI $\dagger$ ). For this purpose, $20 \mu \mathrm{L}$ of the catholyte aliquots was diluted with $1.980 \mathrm{~mL}$ Milli-Q water and mixed with $1 \mathrm{~mL}$ of $0.05 \mathrm{M}$ $\mathrm{NaClO}_{4}$ (Sigma-Aldrich, reagent grade) solution, $2 \mathrm{~mL}$ of $1 \mathrm{M} \mathrm{NaOH}$ (Sigma-Aldrich, >98.0\%) solution 
containing 5 wt.\% of salicylic acid (Sigma Aldrich, $\geq 99.0 \%$ ) and 5 wt.\% of sodium citrate (Sigma Aldrich, $\geq 99.0 \%$ ), and $200 \mu \mathrm{L}$ of 1 wt.\% of sodium nitroferricyanide (Sigma Aldrich, $\geq 99 \%$ ) solution. After a reaction time of $\sim 1$ hour, UV-VIS absorption spectra were recorded from 450 to $900 \mathrm{~nm}$ with a PerkinElmer Lambda 900 UV/VIS/NIR spectrometer. The characteristic absorption maximum of the indophenol derivative was observed at a wavelength of $\lambda=658 \mathrm{~nm}$. The indophenol (ammonia) quantification was based on calibration curves derived from a dilution series using a standard ammonium ion solution (Sigma Aldrich, analytical standard). Representative calibration measurements are presented in Fig. S7b,c,d, ESI†.

The Faradaic efficiency of ammonia production $\left(\mathrm{FE}_{\mathrm{NH} 3}\right)$ was determined as the ratio of the charge consumed for the $\mathrm{NH}_{3}$ production and the total charge $\left(\mathrm{Q}_{\text {tot }}\right)$ passed through the cell during electrolysis according to

$$
\mathrm{FE}_{\mathrm{NH} 3}=\frac{\mathrm{n} \cdot \mathrm{F} \cdot \mathrm{c}_{\mathrm{NH} 3} \cdot \mathrm{V}}{\mathrm{Q}_{\mathrm{tot}}} \cdot 100 \%
$$

The total charge $Q_{\text {tot }}(\mathrm{C})$ passed through the cell during the electrolysis was determined through integration of the respective electrolysis current $v s$. electrolysis time traces. F refers to the Faraday constant $\left(96485 \mathrm{C} \cdot \mathrm{mol}^{-1}\right), \mathrm{c}_{\mathrm{NH}_{3}}\left(\mathrm{~mol} \cdot \mathrm{L}^{-1}\right)$ denotes the spectroscopically determined $\mathrm{NH}_{3}$ concentration, $\mathrm{V}(\mathrm{L})$ represents the volume of the catholyte $(\mathrm{V}=0.007 \mathrm{~L})$, and $\mathrm{n}$ is the number of transferred electrons. The nitrate to ammonia conversion is a coupled electron-proton reduction involving the transfer of eight electrons according to

$$
\mathrm{NO}_{3}^{-}+9 \mathrm{H}^{+}+8 \mathrm{e}^{-} \rightarrow \mathrm{NH}_{3}+3 \mathrm{H}_{2} \mathrm{O}
$$

or

$$
\mathrm{NO}_{3}^{-}+6 \mathrm{H}_{2} \mathrm{O}+8 \mathrm{e}^{-} \rightarrow \mathrm{NH}_{3}+9 \mathrm{OH}^{-}
$$

depending on the solution $\mathrm{pH}$.

To exclude $\mathrm{NO}_{3}^{-} \mathrm{RR}$ products other than $\mathrm{NH}_{3}$, we probed the concentration of $\mathrm{NO}_{3}^{-}$in the catholyte, as compared with the detected ammonia concentration, over time. $\mathrm{NO}_{3}^{-}$and $\mathrm{NO}_{2}^{-}$(the latter is a possible side-product of the $\mathrm{NO}_{3}^{-} \mathrm{RR}$ ) quantification was based on ion exchange chromatography (IC). IC measurements were performed with a Metrohm 940 Professional IC Vario instrument operated by MagIC Net 3.3 software. Catholyte solutions were diluted 100 times before the IC analysis.

\section{Results and discussion}

\subsection{Preparation and characterization of $\mathrm{Ni}$ foam catalysts}


An important aspect of the $\mathrm{NO}_{3}^{-} \mathrm{RR}$ catalyst design is the creation of high-surface area materials. Most successful catalyst concepts in the field have relied on the use of nanoparticulate (colloidal) catalysts. ${ }^{23,28}$ A clear advantage of this classical approach is that the entire spectrum of mature colloid chemistry can be applied to synthesize nano-objects with various shapes, morphologies, and size distributions. Herein, we introduce and apply an alternative concept of $\mathrm{NO}_{3}^{-} \mathrm{RR}$ catalyst fabrication based on an additive- and template-assisted metal electrodeposition route ${ }^{34,35,41}$, which is demonstrated to be highly versatile and complementary to the common colloid approach of catalyst design. Metal foams offer a large surface area that not only is accessible to reactants but also enables fast, multi-dimensional electron transport pathways. ${ }^{41,42}$ For the creation of highly porous foam type of materials, we use hydrogen gas bubbles as a geometric template that temporarily forms during the primary metal (e.g., Ni) electrodeposition process on both the planar support electrode and the emerging porous catalyst film. The origin of the vigorous hydrogen gas bubble formation is the reductive decomposition of the acidic aqueous plating bath. In this metal foaming process, fairly harsh deposition conditions are applied in the form of high (geometric) current densities (e.g., $-3 \mathrm{~A} \cdot \mathrm{cm}^{-2}$ ). ${ }^{41}$ The source for the HER under these extreme conditions is not only the reduction of protons (reaction $\mathrm{R} 4$ )

$$
2 \mathrm{H}^{+}+2 \mathrm{e}^{-} \rightarrow \mathrm{H}_{2}
$$

but also the reductive splitting of water (reaction R5)

$$
2 \mathrm{H}_{2} \mathrm{O}+2 \mathrm{e}^{-} \rightarrow \mathrm{H}_{2}+2 \mathrm{OH}^{-}
$$

The basic concept of the so-called dynamic hydrogen bubble template (DHBT) deposition process is depicted in Fig. 1a. $\mathrm{H}_{2}$ bubbles are generated by reactions $\mathrm{R} 4$ and $\mathrm{R} 5$, thus disrupting the growth of the Ni layer and consequently acting as a dynamic template. Micropores in the submicron range and macropores in the 10-100 $\mu \mathrm{m}$ size range are formed in the deposit, as a result of the growth of metal around small or larger coalesced bubbles generated on the surface. ${ }^{41}$ With the DHBT method, extreme cathodic overpotentials are used, so that the rates of the primary metal deposition and the secondary HER become comparable and determine the obtained 3D foam architecture. ${ }^{41}$ However, other factors beyond the reaction rates may determine the resulting surface morphology of the deposited metal foam, such as the nucleation, growth, and detachment of the surface generated bubbles; related convective effects caused by bubble formation; local alkalinization of the near-electrode solution layers (R4 and R5) and its consequences on the chemistry of metal deposition; and the action of additives. ${ }^{41}$ Of note, in the present case, both the ammonium cations and the PEG-PPG-PEG polymers act as plating additives (surfactants) influencing hydrogen bubble formation/detachment and the $\mathrm{Ni}$ foam growth characteristics on various length scales. Fig. $1 \mathrm{~b}$ depicts an optical micrograph and an SEM image of a representative Ni foam 
deposited on a planar $\mathrm{Ni}$ foil. In contrast to the support electrode, the electrodeposited Ni foams typically show a black appearance (denoted Ni black, Fig. S2, ESI $\uparrow$ ). Cross-sectional and top-down SEM images of $\mathrm{Ni}$ foams yielded after $5,10,20,40$, and 60 seconds of deposition at $\mathrm{j}_{\text {geo }}=-3 \mathrm{~A} \cdot \mathrm{cm}^{-2}$ are presented in Fig. 2 , and demonstrate the evolution of the foam morphology as a function of the deposition time (additional data in Fig. S9, ESI $\dagger$ ). Clearly, a deposition time of 5 seconds, corresponding to an average Ni film thickness of $\sim 1 \mu \mathrm{m}$, was insufficient to develop a full 3D foam structure. Only after 10 seconds did a network of interconnected open pores start to evolve. In accordance with other examples of metal foam deposition processes ${ }^{34-37}$, the surface pore diameter of the $\mathrm{Ni}$ foam increased with deposition time, as consequence of the continual coalescence of the templating hydrogen bubbles, in this particular case from $\sim 2.6 \mu \mathrm{m}(10 \mathrm{~s})$ to $\sim 8.2 \mu \mathrm{m}(60 \mathrm{~s})$. This increase in the mean surface pore diameter was accompanied by an increase in the foam film thickness and Ni mass loading from $\sim 13 \mu \mathrm{m}(10 \mathrm{~s})$ to $\sim 56 \mu \mathrm{m}(60 \mathrm{~s})$, and from 0.7 and $7.2 \mathrm{mg} \cdot \mathrm{cm}^{-2}$, respectively (Fig. S10, ESI $\dagger$ ). As exemplified in Fig. $2 \mathrm{k}$ for the $20 \mathrm{~s}$ deposition case, the formed Ni foams typically revealed high homogeneity across the Ni support. The Ni pore sidewalls were composed of more "loosely" packed Ni clusters, thereby introducing a secondary porosity on the nanometer length scale to the foam material, which was particularly pronounced in the case of the thicker Ni foams (40 s and $60 \mathrm{~s}$ of deposition). Aggregates of these Ni clusters had a cauliflower-like appearance. Similarly, other foam materials reported in the literature ${ }^{36,43}$ a gradient formed along the surface normal with regard to the pore diameters. Structural data on the formed Ni foams are summarized in Fig. S9 and Fig.S10, and Table S1, ESI†.

The highly porous nature of the electrodeposited Ni foams led to a substantial increase in the surface area. The electrochemically active surface area (ECSA), defining the fraction of the total surface area that is accessible to the aqueous electrolyte and therefore can participate in the electrolysis reaction, is particularly relevant to the electrolysis application. Therefore, the ECSA is among the key parameters for the optimization of the catalyst material, because this quantity scales with the number of accessible active sites on which the electrolysis reaction can occur. In this work, we applied two complementary voltammetric approaches for ECSA determination, based on the measurement and analysis of either capacitive or Faradaic processes (details in the Experimental section). Results of the capacitance method approach (Fig. S5, Fig. S6, and Table S1, ESI $\dagger$ ) indicated an increase in the ECSA from $5.44 \mathrm{~cm}^{2}$ to 12.05 $\mathrm{cm}^{2}$ when the deposition time was extended from 5 to 40 seconds. This trend in increasing surface area was confirmed through a complementary approach using the reversible reduction of dimethyl viologens as a "Faradaic" probe. Scan-rate depending peak currents $\left(I_{p}\right)$ were derived from the respective voltammograms (Fig. S6,) and plotted versus the square root of the applied potential sweep rate $\left(v^{1 / 2}\right)$. The corresponding $\mathrm{I}_{\mathrm{p}} v$ s. $v^{1 / 2}$ plots showed a linear characteristic in all cases, thus verifying that the Randles-Ševčík equation could be applied in this case to non-planar and highly porous electrode 
materials. The obtained ECSA values were in good agreement with those derived on the basis of the capacitive measurements, and changed from $6.78 \mathrm{~cm}^{2}$ to $13.03 \mathrm{~cm}^{2}$ with an increase in deposition time from 5 to 40 seconds (Table S1, ESI†े).

\subsection{Catalytic performance of the $\mathrm{Ni}$ foams toward $\mathrm{NO}_{3}^{-} \mathrm{RR}$}

To evaluate the dependence of the electrocatalytic performance on the foam morphology, we performed potentiostatic electrolyses at two selected potentials of -0.1 and $-0.3 \mathrm{~V} v s$. RHE. For this purpose, $1 \mathrm{M}$ $\mathrm{KOH}(\mathrm{pH}=14)$ solution containing $0.1 \mathrm{M} \mathrm{KNO}_{3}$ as the nitrate source was used as the electrolyte. According to common protocols for $\mathrm{NO}_{3}^{-} \mathrm{RR}$ catalyst screening ${ }^{31}$ strong alkaline conditions were established to suppress the parasitic HER in this potential regime, which could be superimposed on the $\mathrm{NO}_{3}^{-} \mathrm{RR}$ and decrease the (nitrate $\rightarrow$ ammonia) conversion yields. Fig. 3a depicts the resulting (mean) geometric electrolysis current densities $\left(\mathrm{TCD}_{\mathrm{geo}}\right)$ as a function of the elapsed Ni deposition time. For both applied electrolysis potentials, a $\mathrm{TCD}_{\text {geo }}$ increase with the deposition time was observed, owing to changes in the ECSA, which scaled with the time duration of the metal foaming process. However, when normalized to the ECSA, the TCD values became largely independent on the morphological properties (primary/secondary porosity, film thickness, etc.) of the Ni foams (Fig. S11, ESI†). The plot of the corresponding Faradaic efficiencies for ammonia production $\left(\mathrm{FE}_{\mathrm{NH} 3}\right)$, displayed in Fig. 3b, indicates a performance optimum in the range of 20 to 30 seconds of $\mathrm{Ni}$ foam deposition. E.g., for the $20 \mathrm{~s}$ case, outstanding Faradaic ammonia yields of $\mathrm{FE}_{\mathrm{NH} 3}=97.89 \%$ and $\mathrm{FE}_{\mathrm{NH} 3}=95.5 \%$ were obtained for applied electrolysis potentials of $-0.1 \mathrm{~V}$ and $-0.3 \mathrm{~V} v s$. RHE, respectively. A full potential dependent characterization of the catalyst performance (20 s deposition sample) is displayed in Fig. 3c,d and demonstrated an exponential increase in the (total) electrolysis current densities with increasing cathodic potentials (Fig. 3c). As a reference, we added the corresponding data for the Ni foil support, which, in full agreement with the observed differences in the ECSA values (Fig. S6, Table S1, ESI $\dagger$ )), showed substantially lower total electrolysis current densities. Similar potential-dependent trends were derived for the corresponding partial current densities of ammonia production ( $\mathrm{PCD}_{\mathrm{NH} 3-\mathrm{geo}}$ ) displayed in Fig. 3d. $\mathrm{PCD}_{\mathrm{NH} 3 \text {-geo }}$ values were calculated from the corresponding Faradaic efficiencies of ammonia production $\left(\mathrm{FE}_{\mathrm{NH} 3}\right.$, Fig. 3e) and the corresponding total current densities (Fig. 3d). For both the Ni foil reference and the optimized $\mathrm{Ni}$ foam catalyst, a characteristic peak-like behavior was observed in the respective $\mathrm{FE}_{\mathrm{NH} 3}$ $v s$. E plot, with a maximum of ammonia selectivity centered at approximately $-0.2 \mathrm{~V} v s$. RHE. In the case of the Ni foam, the (Faradaic) ammonia yields did not fall below 95\%, even within a relatively broad potential range ( $200 \mathrm{mV}$ wide plateau region) spanning from $-0.1 \mathrm{~V}$ to $-0.3 \mathrm{~V} v s$. RHE, with a maximum of $97.8 \%$ at $-0.1 \mathrm{~V} v s$. RHE. In comparison, the Faradaic yields determined for the Ni foil reference remained at a substantially lower level within the entire potential range studied, with a maximum of only 
$49.5 \%$ at $-0.2 \mathrm{~V} v s$. RHE. Notably, the Ni foam catalyst outperformed not only the planar foil but also the corresponding pure Ni catalysts reported in the literature. ${ }^{31}$ We assume that the steep decrease in the $\mathrm{FE}_{\mathrm{NH} 3}$ values observed for the $\mathrm{Ni}$ foam and the foil at potentials below $-0.3 \mathrm{~V} v s$. RHE (Fig. 3e) was due to the increasingly dominating HER, which was mainly fed at $\mathrm{pH} 14$ by the water reductive splitting (reaction R5). This scenario was further corroborated by voltammetric reference measurements recorded for $\mathrm{Ni}$ foam $(20 \mathrm{~s})$ in the absence (blank) or presence of nitrate in the working electrolyte, showing an onset of massive HER in $1 \mathrm{M} \mathrm{KOH}$ at potentials below $-0.2 \mathrm{~V} v s$. RHE (Fig. S12, ESI $\dagger$ ). In addition to these parasitic HER effects, nitrate mass transport limitations toward and into the Ni foam might become effective during $\mathrm{NO}_{3}^{-} \mathrm{RR}$ at high cathodic potentials (high cathodic current densities), particularly when batch reactors with small electrolyte volume $(7 \mathrm{~mL})$ and a quiescent electrolyte (nor convective mass transport) are used, thus further decreasing the respective ammonia Faradaic yields (Fig. 3e). Of note, in contrast to $\mathrm{NO}_{3}^{-} \mathrm{RR}$, the reductive water splitting did not become mass transport limited.

To exclude nitrogen containing $\mathrm{NO}_{3}^{-} \mathrm{RR}$ products other than ammonia (e.g., $\mathrm{N}_{2}, \mathrm{NO}, \mathrm{N}_{2} \mathrm{O}$, or $\mathrm{NO}_{2}^{-}$), we performed the ammonia analysis in tandem with the quantification of the resulting nitrate concentration by using post-electrolysis IC. The results (Fig. 3f) demonstrated that the detected ammonia $\left(\mathrm{NO}_{3}^{-} \mathrm{RR}\right.$ product) and nitrate $\left(\mathrm{NO}_{3}^{-} \mathrm{RR}\right.$ educt) concentrations indeed added, within the error margins, to $100 \mathrm{mM}$ over the entire potential range studied. Of note, an initial nitrate concentration of $100 \mathrm{mM}$ was used for all electrolysis experiments presented in Fig. 3. These observations demonstrated a $100 \%$ selectivity for the (nitrate $\rightarrow$ ammonia) conversion with use of the novel $\mathrm{Ni}$ foam catalyst. $\mathrm{The}^{\mathrm{NO}_{2}^{-}}$ concentration remained below the detection limit of the ion chromatography.

The presented electrolysis data (Fig. 3, Table S2 and Table S3) revealed that not only the chemical nature and the composition of the catalyst matter, but also its morphology on various length scales influences the resultant product selectivity. A similar dependence of the foam morphology on the product distribution has been reported for other $\mathrm{pH}$ dependent multi-step electrolysis reactions, e.g., by Dutta et al. for the $\mathrm{CO}_{2}$ reduction reaction $\left(\mathrm{CO}_{2} \mathrm{RR}\right)$ performed over electrodeposited $\mathrm{Cu}$ foams of varying porosity. ${ }^{36}$ In that case, improved hydrocarbon selectivity was observed for the applied $\mathrm{Cu}$ foams (in comparison to respective planar catalysts), an effect attributable to the trapping and readsorption of key $\mathrm{CO}_{2} \mathrm{RR}$ intermediates (e.g., $\mathrm{CO}, \mathrm{C}_{2} \mathrm{H}_{4}$ ) inside the pores of the $3 \mathrm{D}$ foam catalyst. ${ }^{36}$

One possible scenario rationalizing the observed excellent catalytic performance of the Ni foam is, in analogy to the $\mathrm{CO}_{2} \mathrm{RR} / \mathrm{Cu}$ foam case ${ }^{36}$, the trapping of formed and partially released $\mathrm{NO}_{3}^{-} \mathrm{RR}$ intermediates $\left(\mathrm{NO}_{2}^{-}, \mathrm{NO}, \mathrm{N}_{2} \mathrm{O}\right.$, Fig. 4) inside the 3D Ni foam catalyst. To experimentally support this statement, we compared electrolysis experiments performed with the $\mathrm{Ni}$ foam (electrodeposited, 20s deposition time) to Ni film catalysts where the primary macroporosity (pore structure) was intentionally eliminated whereas the morphological characteristics on the nm length scale remained conserved (Fig. 4 
and Fig. S13, ESI $\uparrow$ ). Clearly, the foam type of Ni catalysts outperforms the Ni film catalyst fabricated from the respective foam materials proving that the primary macroporosity plays indeed an eminent role. Fig. 5 displays possible reaction pathways discussed in the literature for a variety of $\mathrm{NO}_{3}^{-} \mathrm{RR}$ catalysts. In general, two groups of $\mathrm{NO}_{3}^{-} \mathrm{RR}$ catalysts can be distinguished. The first class, including metals that are highly active toward the HER (e.g., Pd, Pt, and Ru, denoted type I in Fig. 4), reduce nitrate through a hydrogenation reaction pathway involving (pre)adsorbed (atomic) hydrogen. ${ }^{44}$ This aspect might also explain why the $\mathrm{NO}_{3}^{-} \mathrm{RR}$ yields reported for these catalysts are substantially lower than those with, e.g., $\mathrm{Cu}$. The direct competition of adsorbed $\mathrm{H}_{\text {and }} \mathrm{NO}_{3}^{-}$for surface adsorption sites prevents higher Faradaic yields for these metals. Recombination of adsorbed $\mathrm{H}$ species (instead of $\mathrm{NO}_{x}$ hydrogenation) promotes parasitic HER. On metals such as $\mathrm{Cu}$ (denoted type II in Fig. 4), the metal-H bonding is much weaker than that on the first group of metallic catalysts. Therefore, higher surface concentrations of adsorbed $\mathrm{NO}_{3}^{-}$might be achieved in the $\mathrm{Cu}$ case, which in turn could further suppress the parasitic HER through sterically blocking the respective active sites. In the case of $\mathrm{Cu}$, protons are transferred from the solution phase to the adsorbed (partially reduced) $\mathrm{NO}_{x}$ species. Of note, both hydronium cations and water could, in principle, serve as the proton source for the coupled electron/proton transfer reaction (depending on the solution $\mathrm{pH}$ ). We assume that $\mathrm{Ni}$ catalysts and $\mathrm{Cu}$ share the same $\mathrm{NO}_{3}^{-} \mathrm{RR}$ mechanism. However, the maximum of the Faradaic ammonia yield $\left(\mathrm{FE}_{\mathrm{NH} 3}\right)$ is reached at slightly lower applied electrolysis potentials when the $\mathrm{Ni}$ foam is used as the catalyst, thus indicating more energy efficient (nitrate $\rightarrow$ ammonia) conversion on the $\mathrm{Ni}$ than, e.g., the $\mathrm{Cu}$ based catalysts (e.g., $\mathrm{Cu} / \mathrm{Cu}_{2} \mathrm{O}-\mathrm{NWs}, \mathrm{FE}_{\mathrm{NH} 3}=$ $95.8 \%, \mathrm{E}=-0.85 \mathrm{~V} v s . \mathrm{RHE})^{23}$. Further information for reference is provided in Fig. S14, ESI $\dagger$ and Table S6, ESI $\uparrow$. One possible explanation for this experimental observation may be stronger binding of not only the $\mathrm{NO}_{3}^{-}$reactant but also possibly the intermediates $\left(\mathrm{NO}_{2}^{-}, \mathrm{NO}, \mathrm{N}_{2} \mathrm{O}\right)$ to the $\mathrm{Ni}$. We assume that metallic $\mathrm{Ni}$ is the active catalyst. There was no experimental indication for any involvement of hydroxide or oxidic $\mathrm{Ni}$ species in the $\mathrm{NO}_{3}^{-} \mathrm{RR}$ (Fig. S15, ESI $\dagger$ ).

\subsection{Stability of the Ni foams during extended $\mathrm{NO}_{3}^{-} \mathrm{RR}$}

To test the structural stability of the Ni foam catalyst, we performed extended 6 hours electrolysis at -0.3 V vs. RHE (Fig. S16, ESI $\dagger$ )). The identical location (SEM) technique ${ }^{45}$ was applied to probe the morphology of the $\mathrm{Ni}$ foam at the same location of the catalyst surface before and after 6 hours of electrolysis (Fig. 6a-d). Both the primary macroporosity and the nanometer-scale structure of the pore sidewalls remained unaffected by the extended electrolysis, thus demonstrating the high structural stability of the novel $\mathrm{Ni}$ foam catalysts during $\mathrm{NO}_{3}^{-} \mathrm{RR}$. This study provides the first report of the use of cross-sectional SEM/2D-EDX analysis to study the wetting behavior of a foam catalyst (Fig. 6e-g). For this purpose, we applied two-dimensional EDX mapping of potassium to probe the electrolyte penetration 
$\left(1 \mathrm{M} \mathrm{KOH}+0.1 \mathrm{M} \mathrm{KNO}_{3}\right.$ ) into the 3D structure of the Ni foam. The 2D potassium mapping (Fig. $6 \mathrm{~g}$ ) indicated that the full 3D structure of the $\mathrm{Ni}$ foam was wetted by the electrolyte down to the Ni foil support. The same behavior was observed for even the thickest $\mathrm{Ni}$ foam applied in this study (60 $\mathrm{s}$ deposition time, Fig. S17, ESI $\dagger$ ). Of note, the Faradaic efficiency of ammonia production $\left(\mathrm{FE}_{\mathrm{NH} 3}\right)$ decreased over the electrolysis time when a batch reactor with a limited electrolyte volume of $7 \mathrm{~mL}$ was used (Fig. S16, ESI $\dagger$ ). This finding can be rationalized by the consumption of the nitrate reactant in the working electrolyte and inside the 3D foam structure during more extended electrolyses. However, high Faradaic yield of ammonia production can be recovered by electrolyte replenishment, as demonstrated in Fig. 7, in a more extended (discontinuous) catalyst stressing experiment. Two forms of catalyst stress were used in this experiment: one form was applied in through the extended electrolysis itself, and a second more extreme form of stress consisted of the repetitive switching off of electrolysis, also involving the loss of potential control at given electrolysis times (e.g., for the electrolyte replenishment). However, the electrolysis data presented in Fig. 7 suggest that the Ni foam catalyst is sufficiently robust to withstand these various forms of stress.

\section{Conclusions}

In this work, we report the first application of an additive and DHBT assisted electrodeposition process to produce $\mathrm{Ni}$ foam catalysts for highly (energy) efficient (nitrate $\rightarrow$ ammonia) electroreduction $\left(\mathrm{NO}_{3}^{-} \mathrm{RR}\right)$. Optimized Ni foams (20 s deposition time) revealed an outstanding Faradaic efficiency of ammonia production not decreasing below $95 \%$ within a relatively broad potential window of $\sim 200 \mathrm{mV}$ ranging from -0.1 to $-0.3 \mathrm{~V}$ vs. RHE. The highest efficiencies, e.g., $\mathrm{FE}_{\mathrm{NH} 3}=95.99 \%$ at $-0.3 \mathrm{~V} v s$. RHE, were observed at applied electrolysis potentials slightly more positive than those reported for pure $\mathrm{Cu}$ catalysts, which are often considered benchmark for the $\mathrm{NO}_{3}^{-} \mathrm{RR}$. The porous nature of the $\mathrm{Ni}$ foams is associated with a high ECSA and thus is the physical origin of the observed superior partial current densities of ammonia production (e.g., $\mathrm{PCD}_{\mathrm{NH} 3}=-68.4 \mathrm{~mA} \cdot \mathrm{cm}^{-2}$ at $-0.3 \mathrm{~V} v$ s. $\mathrm{RHE} ; \mathrm{PCD}_{\mathrm{NH} 3}=-138.3 \mathrm{~mA} \cdot \mathrm{cm}^{-2}$ at -0.6 V vs. RHE). Post-electrolysis cross-sectional EDX mapping (K tracing) experimentally provided the first demonstration of the complete wetting of this type of foam catalyst by the working electrolyte, down to the layer of the planar support material. Extended 24 hour nitrate electrolysis demonstrated the excellent stability of the Ni foam catalyst. These results are in line with microscopic analyses performed at the same location of the catalyst before and after the electrolysis (through the IL approach).

Our forthcoming studies will apply operando spectroscopic means (specifically infrared and Raman vibrational spectroscopy) to reveal the mechanistic origin of the high Faradic ammonia yields, as observed on the Ni. To address the observed nitrate mass transport effects toward and into the 3D Ni foam and associated losses in the Faradaic yields of ammonia production, we will replace the batch 
reactor design used herein for the initial catalyst screening with more sophisticated electrolyte flow-cell devices with the aim to maintain the observed high partial current densities and Faradaic efficiencies of ammonia production of a high level also during extended electrolyses.

\section{Conflict of interests}

There is no conflict of interests to declare.

\section{Acknowledgments}

This publication was created as part of NCCR Catalysis (grant number 180544), a National Centre of Competence in Research funded by the Swiss National Science Foundation. A.I. acknowledges the financial support by the State Secretariat for Education, Research and Innovation through a Swiss Government Excellence Scholarship for Foreign Scholars.

\section{References}

1. S. Yang and N. Gruber, Global Biogeochem. Cycles, 2016, 30, 1418-1440.

2. J. N. Galloway, J. D. Aber, J. W. Erisman, S. P. Seitzinger, R. W. Howarth, E. B. Cowling and B. J. Cosby, BioScience, 2003, 53, 341-356.

3. N. Gruber and J. N. Galloway, Nature, 2008, 451, 293-296.

4. D. E. Canfield, A. N. Glazer and P. G. Falkowski, Science, 2010, 330, 192-196.

5. J. N. Galloway, A. R. Townsend, J. W. Erisman, M. Bekunda, Z. Cai, J. R. Freney, L. A. Martinelli, S. P. Seitzinger and M. A. Sutton, Science, 2008, 320, 889-892.

6. P. H. van Langevelde, I. Katsounaros and M. T. M. Koper, Joule, 2021, 5, 290-294.

7. I. Katsounaros, M. Dortsiou and G. Kyriacou, J. Hazard. Mater., 2009, 171, 323-327.

8. R. Chauhan and V. C. Srivastava, Chem. Eng. J., 2020, 386, 122065.

9. E. R. Jones, M. T. H. van Vliet, M. Qadir and M. F. P. Bierkens, Earth Syst. Sci. Data, 2021, 13, 237-254.

10. G. Jacks and V. P. Sharma, Environ. Geol., 1983, 5, 61-64.

11. J. F. Su, I. Ruzybayev, I. Shah and C. P. Huang, Appl. Catal. B, 2016, 180, 199-209.

12. S. Ghavam, M. Vahdati, I. A. G. Wilson and P. Styring, Front. Energy Res., 2021, 9, 1-19.

13. L. Wang, M. Xia, H. Wang, K. Huang, C. Qian, C. T. Maravelias and G. A. Ozin, Joule, 2018, 10551074.

14. S. Bunea, K. Clemens and A. Urakawa, ChemSusChem, 2022, 15, e202102180.

15. S. Samatya, N. Kabay, Ü. Yüksel, M. Arda and M. Yüksel, React. Funct. Polym., 2006, 66, 12061214.

16. R. Epsztein, O. Nir, O. Lahav and M. Green, Chem. Eng. J., 2015, 279, 372-378.

17. Y. L. Dong Xu, Lifeng Yin, Yangyuan Ji, Junfeng Niu, Yanxin Yu, Front. Environ. Sci. Eng., 2018, 12, 9. 
18. M. Duca and M. T. M. Koper, Energy Environ. Sci., 2012, 5, 9726-9742.

19. H.-R. M. Jhong, S. Ma and P. J. A. Kenis, Curr. Opin. Chem. Eng., 2013, 2, 191-199.

20. D. T. Whipple and P. J. A. Kenis, J. Phys. Chem. Lett., 2010, 1, 3451-3458.

21. J. L. Qiao, Y. Y. Liu, F. Hong and J. J. Zhang, Chem. Soc. Rev. , 2014, 43, 631-675.

22. A. J. Martín, T. Shinagawa and J. Pérez-Ramírez, Chem, 2019, 5, 263-283.

23. Y. Wang, W. Zhou, R. Jia, Y. Yu and B. Zhang, Angew. Chem. Int. Ed., 2020, 59, 5350-5354.

24. S. Wang, F. Ichihara, H. Pang, H. Chen and J. Ye, Adv. Funct. Mater., 2018, 28, 1803309.

25. M. Kato, M. Okui, S. Taguchi and I. Yagi, J. Electroanal. Chem., 2017, 800, 46-53.

26. S. Taguchi and J. M. Feliu, Electrochim. Acta, 2007, 52, 6023-6033.

27. J. Yang, P. Sebastian, M. Duca, T. Hoogenboom and M. T. M. Koper, Chem. Commun., 2014, 50, 2148-2151.

28. J. Li, G. Zhan, J. Yang, F. Quan, C. Mao, Y. Liu, B. Wang, F. Lei, L. Li, A. W. M. Chan, L. Xu, Y. Shi, Y. Du, W. Hao, P. K. Wong, J. Wang, S.-X. Dou, L. Zhang and J. C. Yu, J. Am. Chem. Soc., 2020, 142, 7036-7046.

29. R. Abdallah, F. Geneste, T. Labasque, H. Djelal, F. Fourcade, A. Amrane, S. Taha and D. Floner, J. Electroanal. Chem., 2014, 727, 148-153.

30. G. E. Dima, A. C. A. de Vooys and M. T. M. Koper, J. Electroanal. Chem., 2003, 554-555, 15-23.

31. Y. Wang, A. Xu, Z. Wang, L. Huang, J. Li, F. Li, J. Wicks, M. Luo, D.-H. Nam, C.-S. Tan, Y. Ding, J. Wu, Y. Lum, C.-T. Dinh, D. Sinton, G. Zheng and E. H. Sargent, J. Am. Chem. Soc., 2020, 142, 5702-5708.

32. W. Zheng, L. Zhu, Z. Yan, Z. Lin, Z. Lei, Y. Zhang, H. Xu, Z. Dang, C. Wei and C. Feng, Environ. Sci. Technol., 2021, 55, 13231-13243.

33. Y. Zhang, Y. Zhao, Z. Chen, L. Wang, P. Wu and F. Wang, Electrochim. Acta, 2018, 291, 151-160.

34. H. C. Shin, J. Dong and M. Liu, Adv. Mater., 2004, 16, 237-240.

35. H. C. Shin and M. Liu, Chem. Mater., 2004, 16, 5460-5464.

36. A. Dutta, M. Rahaman, N. C. Luedi, M. Mohos and P. Broekmann, ACS Catal., 2016, 6, 38043814.

37. A. Dutta, M. Rahaman, B. Hecker, J. Drnec, K. Kiran, I. Zelocualtecatl Montiel, D. Jochen Weber, A. Zanetti, A. Cedeño López, I. Martens, P. Broekmann and M. Oezaslan, J. Catal., 2020, 389, 592-603.

38. A. Dutta, M. Rahaman, M. Mohos, A. Zanetti and P. Broekmann, ACS Catal., 2017, 7, 5431-5437.

39. A. Dutta, I. Z. Montiel, R. Erni, K. Kiran, M. Rahaman, J. Drnec and P. Broekmann, Nano Energy, 2020, 68, 104331.

40. A. Dutta, I. Zelocualtecatl Montiel, K. Kiran, A. Rieder, V. Grozovski, L. Gut and P. Broekmann, ACS Catal., 2021, 11, 4988-5003.

41. S. Vesztergom, A. Dutta, M. Rahaman, K. Kiran, I. Zelocualtecatl Montiel and P. Broekmann, ChemCatChem, 2021, 13, 1039-1058. 
42. W. Zhu, R. Zhang, F. Qu, A. M. Asiri and X. Sun, ChemCatChem, 2017, 9, 1721-1743.

43. A. Dutta, K. Kiran, M. Rahaman, I. Z. Montiel, P. Moreno-García, S. Vesztergom, J. Drnec, M. Oezaslan and P. Broekmann, Chimia, 2021, 75, 733-743.

44. X. Zhang, Y. Wang, C. Liu, Y. Yu, S. Lu and B. Zhang, Chem. Eng. J., 2021, 403, 126269.

45. M. Rahaman, A. Dutta, A. Zanetti and P. Broekmann, ACS Catal., 2017, 7, 7946-7956. 


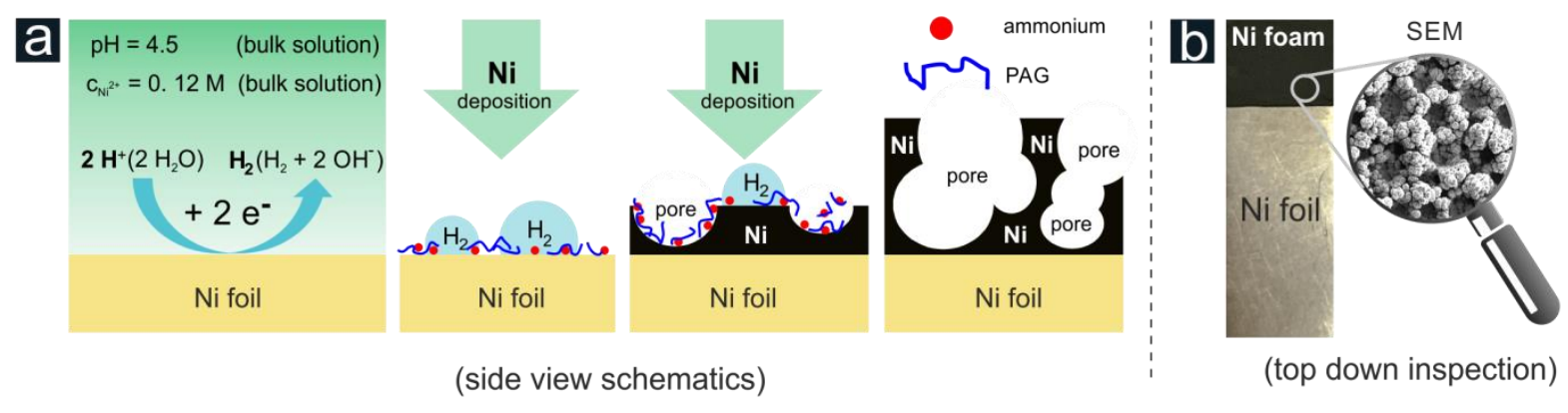

Fig. 1. a) Schematic drawing demonstrating the basic concept of the dynamic hydrogen bubble (DHBT) and additive (e.g., polyalkylene glycol, PAG) assisted metal foam deposition. b) Optical and SEM micrographs of a representative $\mathrm{Ni}$ foam (Ni black) deposited on a Ni foil support electrode. 

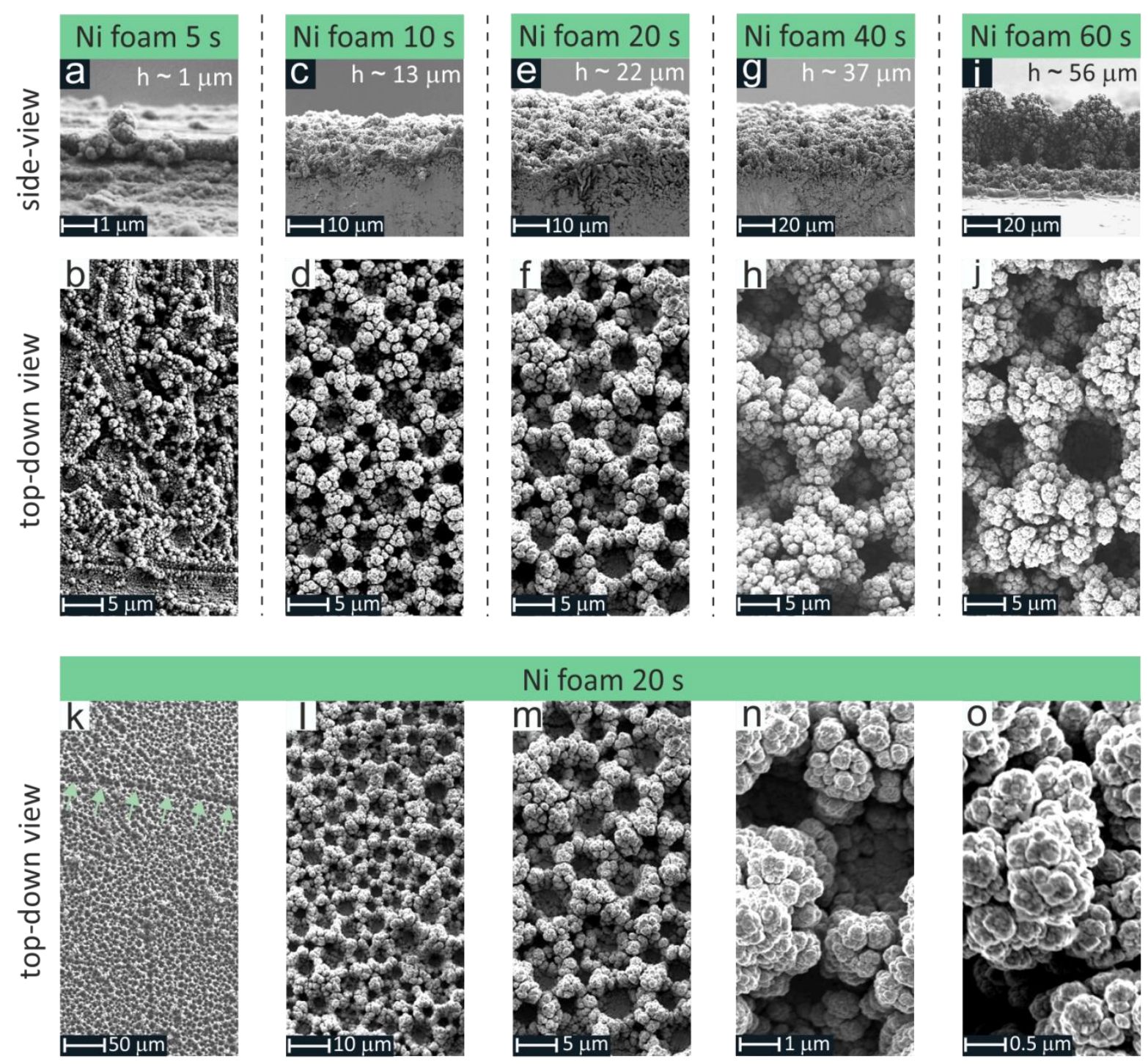

\section{$\mathrm{Ni}$ foam $20 \mathrm{~s}$}
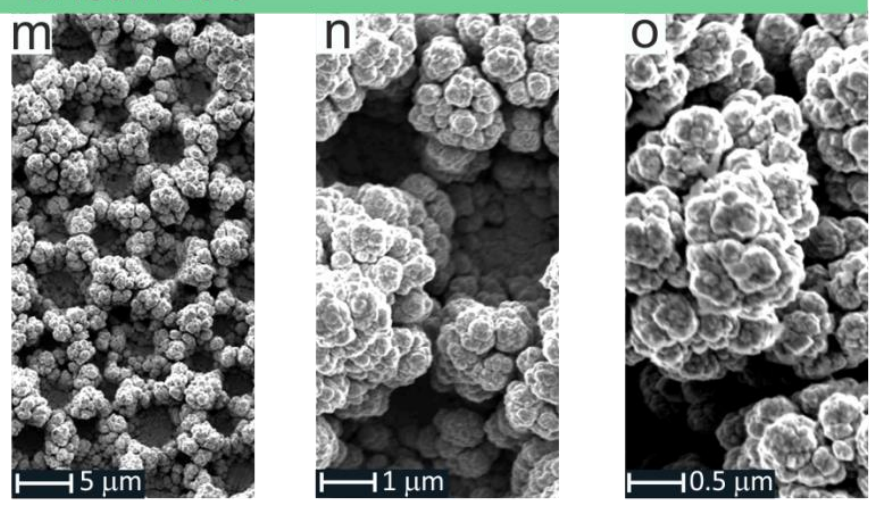

Fig. 2. a-j) Cross-sectional and top-down SEM micrographs showing the evolution of the foam morphology as a function of the deposition time (complete data set presented in Fig. S9). k-o) Top-down SEM micrographs of increasing magnification, showing the structural and morphological characteristics of the Ni foam yielded after $20 \mathrm{~s}$ of deposition. The green arrows in panel $\mathrm{k}$ indicate local imperfections in the foam structure originating from surface scratches in the Ni support (Fig. S1). 

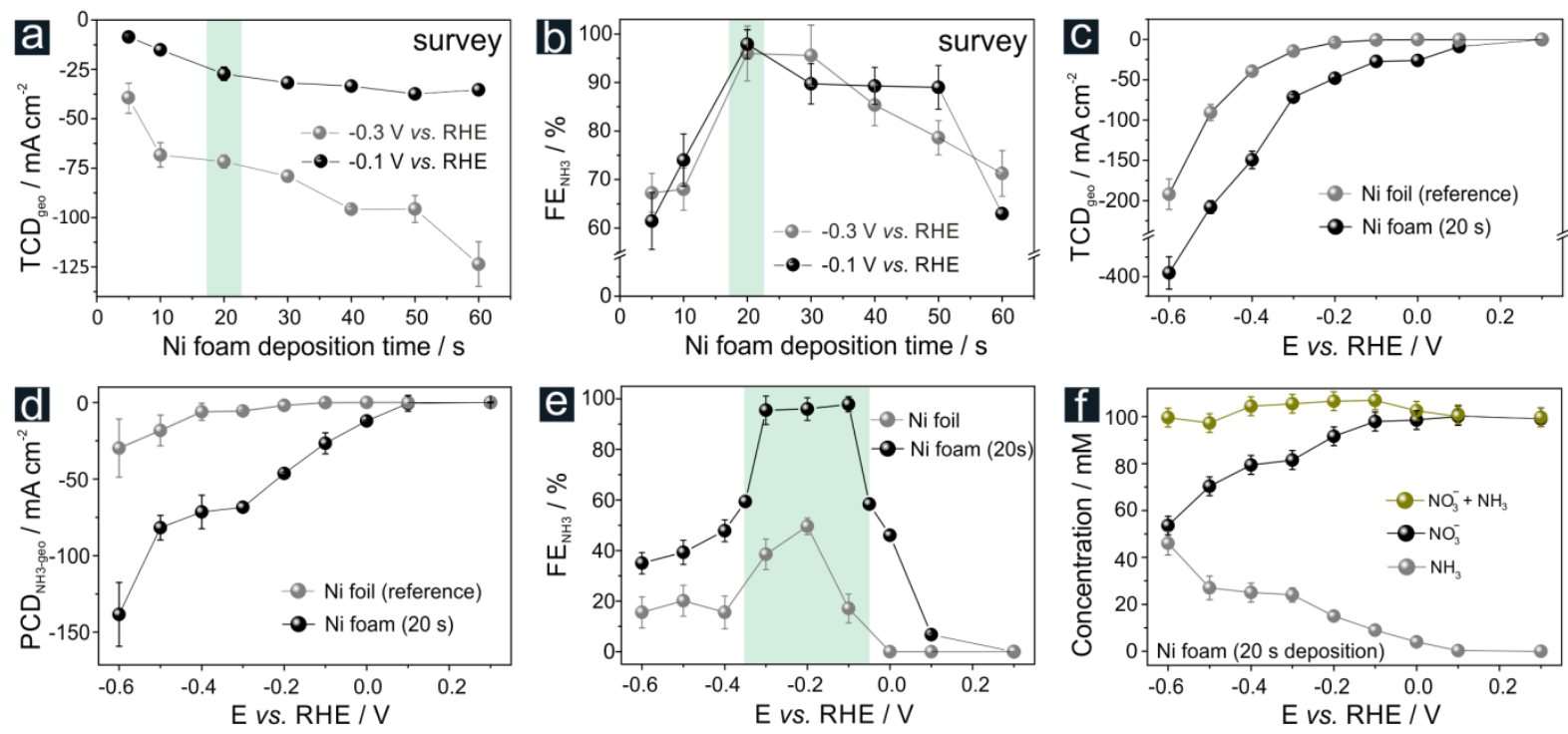

Fig. 3. a) Mean total electrolysis current densities (denoted $\mathrm{TCD}_{\text {geo }}$, normalized to the geometric surface area of $1 \mathrm{~cm}^{2}$ ), determined at electrolysis potentials of -0.1 and $-0.3 \mathrm{~V}$ vs. the RHE. Resulting $\mathrm{TCD}_{\text {geo }}$ values are shown as a function of $\mathrm{Ni}$ foam deposition time. b) Faradaic efficiencies of ammonia production $\left(\mathrm{FE}_{\mathrm{NH} 3}\right)$, corresponding to panel a. c) Potential dependent (mean) total current densities $\left(\mathrm{TCD}_{\mathrm{geo}}\right)$, determined for the blank Ni foil (reference) and the optimized Ni foam (20 s deposition time). c) Potential-dependent partial current densities of ammonia formation $\left(\mathrm{PCD}_{\mathrm{NH} 3 \text {-geo }}\right.$ ) corresponding to panel c. d) Potential-dependent Faradaic efficiencies of ammonia formation $\left(\mathrm{FE}_{\mathrm{NH} 3}\right)$ corresponding to panel $\mathrm{c}$ and d. f) Nitrate and ammonia concentrations detected in the electrolyte after the potential dependent electrolysis. The time duration of the electrolysis experiments presented in Fig. 3 was 30 min. (Of note, the numerical data associated to Fig. 3 can be found in Table S2-S5, ESI $\dagger$ ). 


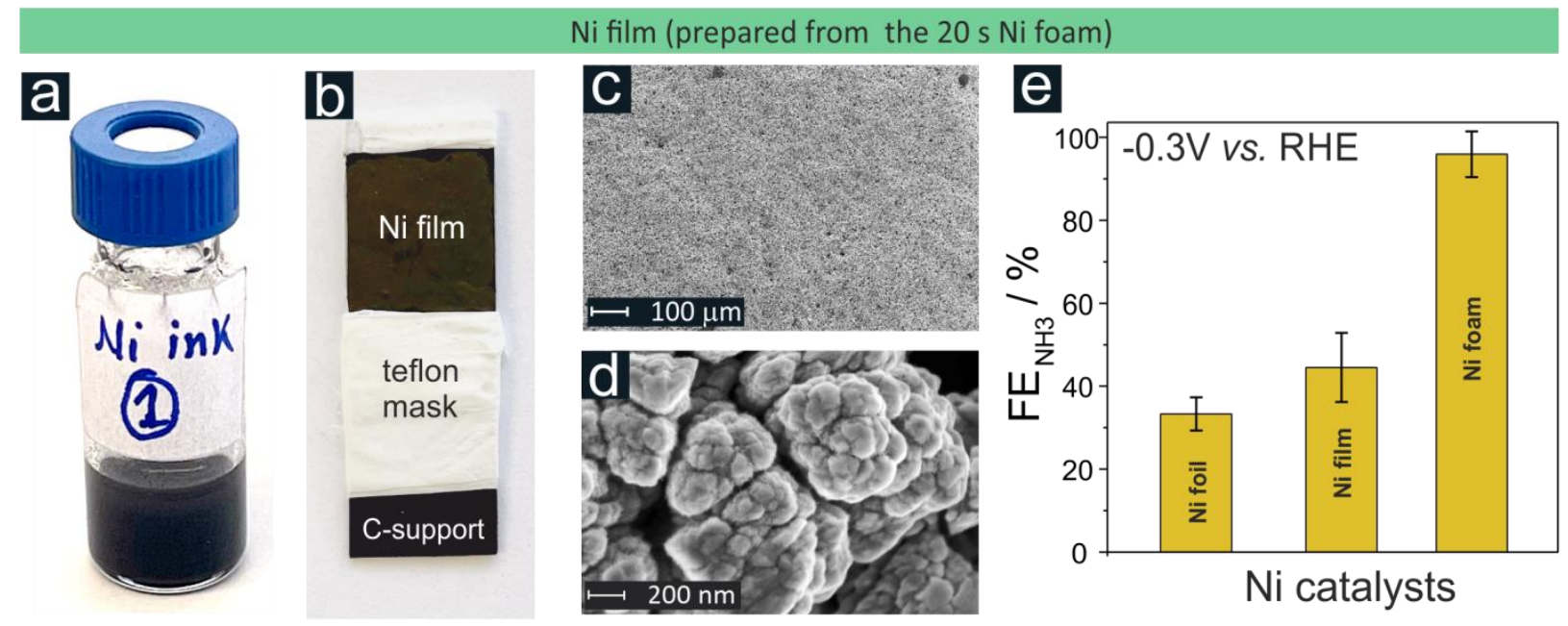

Fig. 4: a) Ni ink prepared from the Ni Foam (20 s deposition time). b) Ni film deposited from the ink on a carbon support. c) - d) Top-down SEM images of the Ni film; e) Comparison of the Faradaic efficiencies following $30 \mathrm{~min}$. electrolysis at $-0.3 \mathrm{~V} v \mathrm{~s}$. RHE. 


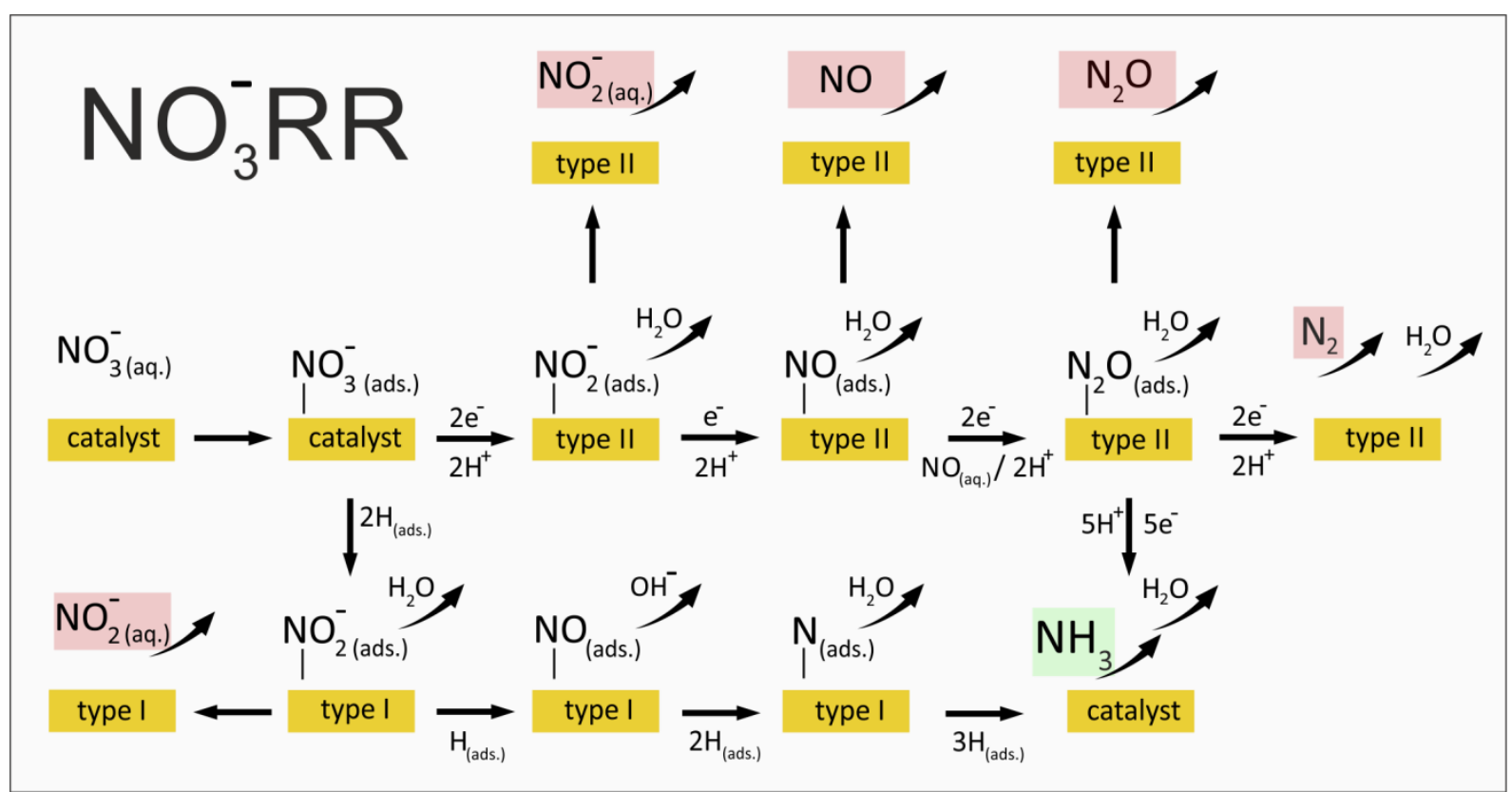

Fig. 5. Possible $\mathrm{NO}_{3}^{-} \mathrm{RR}$ mechanisms. The targeted $\mathrm{NO}_{3}^{-} \mathrm{RR}$ products, ammonia is highlighted in green, and the non-desired by-products are highlighted in red. Type I catalysts include Pt, Pd, and Ru. Type II catalysts include $\mathrm{Cu}$ and $\mathrm{Ni}$. 

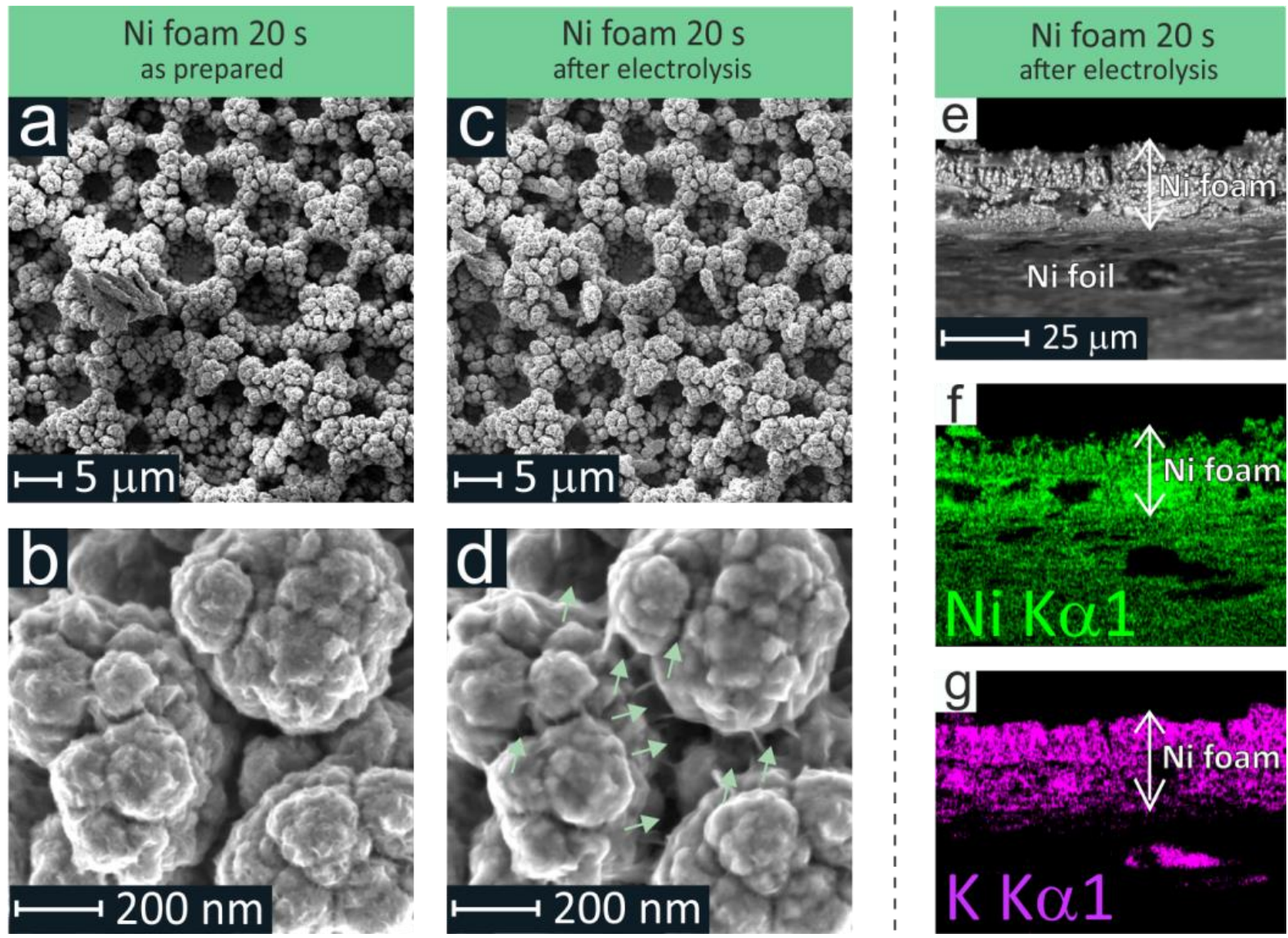

Fig. 6. a-d) Identical location (IL) top-down SEM characterization of the Ni foam catalyst $(20 \mathrm{~s}$ deposition time) before and after electrolysis (30 min at -0.3 V vs. RHE). e-f) Cross-sectional SEM and 2D-EXD analysis of the Ni foam after the electrolysis. The K mapping (panel f) indicates wetting of the $\mathrm{Ni}$ foam catalyst down to the $\mathrm{Ni}$ foil support. 


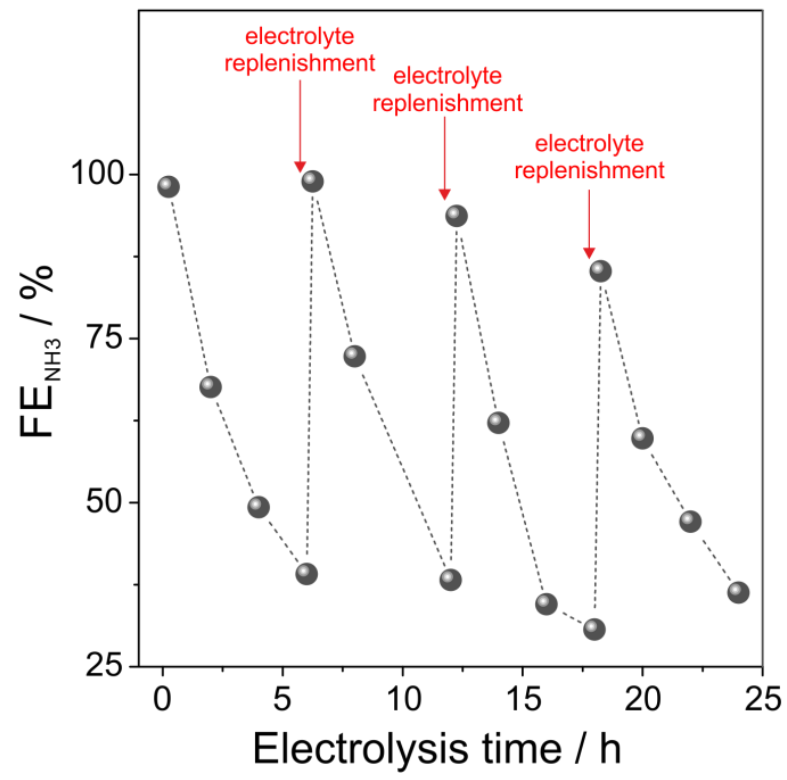

Fig. 7. Discontinuous long-term stress experiment of the $20 \mathrm{~s} \mathrm{Ni}$ foam catalyst (Fig. 2). The electrolyses were performed for 24 hours in $1 \mathrm{M} \mathrm{KOH}+0.1 \mathrm{M} \mathrm{KNO}_{3}$ solution at an applied potential of $-0.3 \mathrm{~V} v s$. RHE. As indicated in the graph, the electrolyses were interrupted at certain electrolysis times, and the electrolyte was replenished in intervals of 6 hours. 